\title{
Effect of 6 weeks' consumption of $\beta$-glucan-rich oat products on cholesterol levels in mildly hypercholesterolaemic overweight adults
}

\author{
Karen E. Charlton ${ }^{1,2 *}$, Linda C. Tapsell ${ }^{1}$, Marijka J. Batterham ${ }^{3}$, Jane O'Shea ${ }^{1}$, Rebecca Thorne ${ }^{1}$, \\ Eleanor Beck ${ }^{1}$ and Susan M. Tosh ${ }^{4}$ \\ ${ }^{1}$ Smart Foods Centre, University of Wollongong, Wollongong, NSW 2522, Australia \\ ${ }^{2}$ School of Health Sciences, University of Wollongong, Wollongong, NSW 2522, Australia \\ ${ }^{3}$ Statistical Consulting Service, University of Wollongong, NSW 2522, Australia \\ ${ }^{4}$ Guelph Food Research Centre, Agriculture and Agri-Food, Guelph, ON, Canada
}

(Submitted 15 March 2011 - Final revision received 14 June 2011 - Accepted 15 June 2011 - First published online 3 August 2011)

\section{Abstract}

Several regulatory bodies have approved a health claim on the cholesterol-lowering effects of oat $\beta$-glucan at levels of $3.0 \mathrm{~g} / \mathrm{d}$. The present study aimed to test whether $1.5 \mathrm{~g} / \mathrm{d} \beta$-glucan provided as ready-to-eat oat flakes was as effective in lowering cholesterol as $3.0 \mathrm{~g} / \mathrm{d}$ from oats porridge. A 6-week randomised controlled trial was conducted in eighty-seven mildly hypercholesterolaemic ( $\geq 5 \mathrm{mmol} / 1$ and $<7.5 \mathrm{mmol} / \mathrm{l})$ men and women assigned to one of three diet arms (25\% energy (E\%) protein; $45 \mathrm{E} \%$ carbohydrate; $30 \mathrm{E} \%$ fat, at energy requirements for weight maintenance): (1) minimal $\beta$-glucan (control); (2) low-dose oat $\beta$-glucan (1.5 g $\beta$-glucan; oats low - OL) or (3) higher dose oat $\beta$-glucan (3.0 g $\beta$-glucan; oats high - OH). Changes in total cholesterol and LDL-cholesterol (LDL-C) from baseline were assessed using a linear mixed model and repeated-measures ANOVA, adjusted for weight change. Total cholesterol reduced significantly in all groups $(-7.8$ (sD 13.8) \%, -7.2 (sD 12.4) \% and -5.5 (SD 9.3) \% in the OH, OL and control groups), as did LDL-C ( -8.4 (SD 18.5) \%, - 8.5 (SD 18.5) \% and -5.5 (SD 12.4) $\%$ in the OH, OL and control groups), but between-group differences were not significant. In responders only $(n 60), \beta$-glucan groups had higher reductions in LDL-C $(-18 \cdot 3$ (SD $11 \cdot 1) \%$ and $-18 \cdot 1$ (SD $9 \cdot 2) \%$ in the OH and OL groups) compared with controls $(-11.7$ (sD 7.9$) \% ; P=0.044)$. Intakes of oat $\beta$-glucan were as effective at doses of $1.5 \mathrm{~g} / \mathrm{d}$ compared with $3 \mathrm{~g} / \mathrm{d}$ when provided in different food formats that delivered similar amounts of soluble $\beta$-glucan.

\section{Key words: Cholesterol: Oats: $\beta$-Glucans: Solubility: Dosage}

The viscous soluble fibre found in oats $((1 \rightarrow 3),(1 \rightarrow 4)$ $\beta$-D-glucan) has been demonstrated to have cholesterollowering effects ${ }^{(1,2)}$. However, despite the majority of trials showing a cholesterol-lowering effect in hypercholesterolaemic subjects, no clear dose-response relationship has been demonstrated.

In addition, not all oat products show similar effects ${ }^{(3-5)}$. The cholesterol-lowering properties appear to be linked to the physico-chemical properties of the soluble $\beta$-glucan fraction, rather than the total soluble fibre content per $s e^{(6)}$. Putative effects have been attributed to an influence on the sequestering of bile acids in the gut, reducing re-absorption and return to the liver for further synthesis ${ }^{(7-9)}$. The direct effects of oat bran on cholesterol levels might also be better seen in the immediate postprandial period through a dramatic effect on decreased chylomicron cholesterol ${ }^{(10)}$

The cholesterol-lowering effects of $\beta$-glucan may be influenced by a number of factors, primarily the molecular weight, solubility and viscosity in the product (as consumed) and these are dependent on the food microstructure, dosage and the type of food processing that has been undertaken. For example, the process of enrichment may affect efficacy ${ }^{(3)}$ Possible unfavourable structural changes that occur to $\beta$-glucan during commercial extraction include depolymerisation of the linear structure which decreases molecular weight and viscosity ${ }^{(11)}$. Under mild extraction conditions, endogenous $\beta$-glucanase enzymes may not be deactivated and thereby further increase depolymerisation ${ }^{(12)}$ which could lower efficacy. Endogenous $\beta$-glucanase enzymes are also active during food preparation ${ }^{(13)}$, causing degradation of $\beta$-glucan in food products. In addition, freezing and storage may reduce the extractability of $\beta$-glucan in the intestine ${ }^{(14)}$ On the other hand, processes in which oats are heated in the presence of water, such as baking, boiling and extru$\operatorname{sion}^{(15,16)}$, increase the solubility of $\beta$-glucan and viscosity which has been associated with an increase in bioactivity ${ }^{(6,17)}$

Abbreviations: E\%, percentage of energy; LDL-C, LDL-cholesterol; OH, oats high; OL, oats low; RTE, ready-to-eat.

*Corresponding author: Dr K. E. Charlton, fax +6124221 4844, email karenc@uow.edu.au 
Variation is in part explained by the physico-chemical properties of the $\beta$-glucan in the food and the diet overall ${ }^{(18)}$. Thus, the level of $\beta$-glucan administered is not the only factor to consider when evaluating the science.

In 1997, the US Food and Drug Administration ${ }^{(19)}$ approved health claims for oat fibre, based on the relationship demonstrated between dietary soluble $\beta$-glucan fibre and a decrease in serum cholesterol concentrations. The Food and Drug Administration has concluded that fibre is efficacious in lowering total cholesterol and LDL-cholesterol (LDL-C) by about $5-10 \%$, at doses of $3 \mathrm{~g} / \mathrm{d}$ from either oat bran or rolled oats. This amount is provided by approximately $55 \mathrm{~g}$ oat bran (minimum $5.5 \% \beta$-glucan) or 75 g rolled oats ( $4 \% \beta$-glucan). More recently, the European Food Safety Authority ${ }^{(20)}$, French Agency for Food, Environment and Occupational Health \& Safety ${ }^{(21)}$, the Joint Health Claims Initiative in the UK and the Food Directorate, Health Products and Food Branch of Health Canada have permitted claims for cholesterol-lowering effects at this level of $\beta$-glucan intake ${ }^{(22)}$.

The present study aimed to assess the ability of two different doses of oat $\beta$-glucan delivered in different food formats (rolled oat porridge, a cereal bar and ready-to-eat (RTE) oat flake breakfast cereal) to lower cholesterol in mildly hypercholesterolaemic Australian adults.

\section{Methods \\ Participants}

The present study was a 6-week parallel, randomised, controlled, single-blind trial conducted with three arms. The two intervention groups were provided with oat porridge and oat-based cereal bars (group oats high $(\mathrm{OH})$, higher $\beta$-glucan, $3.2 \mathrm{~g} / \mathrm{d}$ ) and RTE oat flakes and puffed rice and wheat bars (group oats low (OL), lower $\beta$-glucan, $1.5 \mathrm{~g} / \mathrm{d}$ ), respectively. The control group (minimal $\beta$-glucan) received cornflakes, puffed rice and wheat bars in plain packs.

Volunteers for the study were recruited via advertisements in the local media, including newspaper, television and radio. Approaches were also made to local medical practices, ambulance and fire services and via university staff emails. Inclusion criteria were as follows: men 25-75 years and premenopausal women $>25$ years or 5 years postmenopause (but not on hormone replacement therapy) with total serum cholesterol $\geq 5$ and $<7.5 \mathrm{mmol} / \mathrm{l}$; BMI $>20$ and $<32 \mathrm{~kg} / \mathrm{m}^{2}$; regular breakfast cereal consumer (four to five times/week); stable weight (within $3 \mathrm{~kg}$ over past 3-6 months); and of general good health. Exclusion criteria include the following: major illnesses (including diabetes mellitus, known CHD and chronic renal failure); lipid-lowering medication; familial hypercholesterolaemia; fasting glucose $>5.6 \mathrm{mmol} / \mathrm{l}$; total cholesterol $>7.5 \mathrm{mmol} / \mathrm{l}$; taking dietary supplements that could influence cholesterol (e.g. fish oil); pregnancy/ lactation; food allergies or habits inhibiting compliance with the study design; illiteracy and inadequate conversational English.

The present study was conducted according to the guidelines laid down in the Declaration of Helsinki and all procedures involving human subjects/patients were approved by the Human Research Ethics Committee of the University of Wollongong (HE08/036). Written informed consent was obtained from all participants.

\section{Baseline period}

After eligibility had been determined on the basis of a telephonic interview and a fasting screening blood test to assess total cholesterol concentrations, eligible participants completed a computerised $7 \mathrm{~d}$ diet-history interview (DietAdvice, Xyris Software, 2009; Highgate Hill, QLD, Australia) to assess habitual nutrient intake. Dietary data were analysed using the FoodWorks software system (Xyris Software, version 5, 2007). Nutrient intake data were analysed in terms of energy and macronutrients using the AusNut (Allfoods) Revision 18 database. At 1 week later, eligible participants were randomly assigned to one of three diet groups and attended the university clinic for a dietary counselling session with a dietitian.

\section{Randomisation and concealment}

Randomisation was performed by a researcher independent of the subject interface using the RALLOC command in STATA (version 10.1; College Station, TX, USA). The procedure was stratified by sex and used permuted blocks, with the size and order of the blocks being random. All test foods were packaged in plain, opaque coded wrapping at the point of manufacturing and factory packaging. Since dietary advice was given in terms of food groups, it was not possible to blind the dietitians, but the participants were not informed as to their diet group allocation.

\section{Interventions}

Test foods. The between-group dietary difference occurred with the provision of alternative cereal foods in plain individual portion packs, batch packaged and provided by Cereal Partners Worldwide Limited (Rutherglen, VIC, Australia). Participants were required to consume one packet of cereal and one cereal bar per $d$ with a minimum of five of each per week. $\beta$-Glucan analyses (AOAC (Association of official Analytical Chemists) 995.16) of the products were provided by Medallion Labs, Minneapolis, MN, USA. Cereal bars contained $1.99 \% \beta$-glucan; RTE oat flakes, $2.42 \% \beta$-glucan; and oat porridge, $4 \cdot 17 \% \beta$-glucan. Control foods (RTE cornflakes and puffed rice bars with no $\beta$-glucan) were not analysed as maize and rice do not contain significant quantities of $\beta$-glucan. The amount of $\beta$-glucan provided in the product servings is shown in Table 1 . The $\mathrm{OH}$ group received $3.24 \mathrm{~g}$ $\beta$-glucan $/ \mathrm{d}$ and the OL group received $1.45 \mathrm{~g} \beta$-glucan $/ \mathrm{d}$. The viscosity, solubility and molecular weight of all test foods were analysed by the Guelph Food Research Centre, Agriculture and Agri-Food, Canada. $\beta$-Glucan was extracted from the food samples (10 g dry weight basis) using conditions similar to those found in the upper gastrointestinal system. The extraction was done on $10 \mathrm{~g}$ of food at $37^{\circ} \mathrm{C}$ with digestive enzymes. The physiological extraction and characterisation of soluble $\beta$-glucans were carried out as described previously ${ }^{(23)}$. 
Table 1. Physico-chemical properties of test foods

(Mean values and standard deviations)

\begin{tabular}{|c|c|c|c|c|c|c|c|}
\hline \multirow{3}{*}{$\begin{array}{l}\text { Treatments } \ldots \\
\text { Test foods }\end{array}$} & \multicolumn{4}{|c|}{$\mathrm{OH}$} & \multirow{2}{*}{\multicolumn{3}{|c|}{$\frac{\mathrm{OL}}{\mathrm{RTE} \text { oat flakes }}$}} \\
\hline & \multicolumn{2}{|c|}{ Rolled oats } & \multicolumn{2}{|c|}{ Cereal bar } & & & \\
\hline & Mean & SD & Mean & SD & Mean & & SD \\
\hline Serving size (g) & \multicolumn{2}{|c|}{60} & \multicolumn{2}{|c|}{36} & \multicolumn{3}{|c|}{60} \\
\hline$\beta$-Glucan content (\%) & $4 \cdot 17$ & 0.07 & 1.99 & 0.03 & 2.42 & & 0.04 \\
\hline Dose (g $\beta$-glucan/d) & \multicolumn{2}{|c|}{2.52} & \multicolumn{2}{|c|}{0.72} & \multicolumn{3}{|c|}{1.45} \\
\hline Extract viscosity ( $\mathrm{mPa}$ s at 32 per second) ${ }^{*}$ & $16 \cdot 03$ & 0.48 & $3 \cdot 80$ & 0.12 & 3.78 & & 0.09 \\
\hline Solubility ( $\%$ total $\beta$-glucan) & 35.93 & 0.35 & 24.09 & $1 \cdot 38$ & $90 \cdot 62$ & & 0.39 \\
\hline$C(\mathrm{~g}$ soluble $\beta$-glucan/d) & \multicolumn{2}{|c|}{0.91} & \multicolumn{2}{|c|}{0.17} & \multicolumn{3}{|c|}{1.32} \\
\hline$M_{\mathrm{p}}(\mathrm{g} / \mathrm{mol})$ & 2100000 & 23000 & 2400000 & 146000 & 760000 & & 9200 \\
\hline$M_{\mathrm{p}} \times C(\mathrm{~kg} / \mathrm{mol} \times \mathrm{g} / \mathrm{d})$ & \multicolumn{2}{|c|}{1900} & \multicolumn{2}{|c|}{400} & \multicolumn{3}{|c|}{1000} \\
\hline
\end{tabular}

$\mathrm{OH}$, oats high; OL, oats low; RTE, ready-to-eat; $C$, daily dose of soluble $\beta$-glucan; $M_{\mathrm{p}}$, peak molecular weight.

${ }^{*}$ Viscosity of physiological extract from $10 \mathrm{~g}$ cereal.

The viscosity of the extract was measured using a rheometer with a cone-and-plate configuration. The solubility of $\beta$-glucan was calculated from the total $\beta$-glucan and the amount solubilised during the extraction process. The molecular weight of $\beta$-glucan in solution was analysed using size-exclusion HPLC. Measurements were done on duplicate extractions.

Dietary prescription. Each group was advised by Accredited Practising Dietitians on a healthy low-fat diet utilising the core food groups outlined in the Australian Guide to Healthy Eating ${ }^{(24)}$. Energy intakes were calculated to equate to individuals' estimated energy requirements for weight maintenance using the Mifflin equation ${ }^{(25)}$ and applying a physical activity factor of $1 \cdot 25$. Cereals and cereal bars provided were modelled into the dietary prescription to achieve macronutrient intakes of approximately $45-50 \%$ carbohydrates, 20-25\% energy ( $\mathrm{E} \%$ ) protein and $25-30 \mathrm{E} \%$ fat (Table 2). Participants were provided with educational material and eating plans. Participants were instructed not to eat products which would otherwise alter cholesterol such as those containing plant sterols and fish oil $/ n-3$ supplements while in the study and were given details of such foods.
Dietitians monitored participants throughout the study at follow-up appointments at 3 and 6 weeks.

Participants were issued with a diet compliance booklet in which they noted how many serves from each food group were consumed daily and completed a checklist of the number of packets of cereal or study bars consumed. Diet compliance booklets were returned at completion of the study.

\section{Procedures}

Each participant attended the University clinic to receive their 3-week supply of study foods and for dietary assessment and dietary counselling at commencement of the study and after 3 weeks. Measurements were taken at the 3-week follow-up visit and at the final 6-week visit. Blood samples were collected by qualified phlebotomists and sent for analysis at a quality-assured pathology laboratory (Southern IML Pathology, Wollongong, NSW, Australia). Insulin resistance was assessed using the homeostasis model assessment (HOMA) calculator (version 2.2.2, 12 December 2007; www.dtu.ox.ac.uk). Anthropometric measurements and blood

Table 2. Baseline characteristics of the study subjects (Mean values and standard deviations)

\begin{tabular}{|c|c|c|c|c|c|c|}
\hline \multirow[b]{2}{*}{ Variables } & \multicolumn{2}{|c|}{$\mathrm{OH}(n 30)$} & \multicolumn{2}{|c|}{$\mathrm{OL}(n 28)$} & \multicolumn{2}{|c|}{ Control ( $n$ 32) } \\
\hline & Mean & SD & Mean & SD & Mean & SD \\
\hline Age (years) & 52.43 & $10 \cdot 46$ & 51.93 & 9.87 & 49.75 & $10 \cdot 42$ \\
\hline Height $(m)$ & 1.69 & 0.078 & 1.69 & 0.11 & 1.71 & 0.09 \\
\hline Weight (kg) & 77.06 & $10 \cdot 67$ & 77.87 & $16 \cdot 35$ & $81 \cdot 13$ & $14 \cdot 21$ \\
\hline BMI $\left(\mathrm{kg} / \mathrm{m}^{2}\right)$ & $26 \cdot 74$ & 2.95 & $27 \cdot 28$ & $5 \cdot 33$ & $27 \cdot 74$ & 3.88 \\
\hline Body fat (\%) & 30.98 & $8 \cdot 11$ & $32 \cdot 10$ & 9.27 & 32.44 & 9.66 \\
\hline Waist $(\mathrm{cm})$ & 93.60 & 7.07 & 92.91 & 13.48 & $96 \cdot 36$ & 11.31 \\
\hline $\mathrm{Hip}(\mathrm{cm})$ & 104.43 & $7 \cdot 80$ & $103 \cdot 63$ & $12 \cdot 69$ & $105 \cdot 69$ & 9.53 \\
\hline $\mathrm{SBP}(\mathrm{mmHg})$ & $128 \cdot 76$ & 20.65 & $132 \cdot 12$ & $17 \cdot 17$ & $131 \cdot 78$ & $20 \cdot 37$ \\
\hline $\mathrm{DBP}(\mathrm{mmHg})$ & $76 \cdot 39$ & $12 \cdot 19$ & 77.07 & $10 \cdot 69$ & $78 \cdot 21$ & $8 \cdot 11$ \\
\hline Cholesterol $(\mathrm{mmol} / \mathrm{l})$ & 5.97 & 0.55 & $6 \cdot 12$ & 0.54 & 6.03 & 0.58 \\
\hline TAG (mmol/l) & 1.37 & 0.59 & 1.53 & 0.73 & 1.56 & 0.70 \\
\hline $\mathrm{HDL}(\mathrm{mmol} / \mathrm{l})$ & 1.53 & 0.31 & 1.61 & 0.56 & 1.45 & 0.37 \\
\hline Cholesterol:HDL ratio & 4.06 & 0.83 & 4.26 & 1.51 & $4 \cdot 36$ & 1.01 \\
\hline LDL (mmol/l) & $3 \cdot 82$ & 0.56 & 3.84 & 0.67 & 3.86 & 0.55 \\
\hline Glucose $(\mathrm{mmol} / \mathrm{l})$ & 4.85 & 0.46 & 4.96 & 0.53 & 4.86 & 0.38 \\
\hline Insulin (pmol/l) & 61.9 & $27 \cdot 2$ & $70 \cdot 6$ & 57.6 & 63.2 & 33.8 \\
\hline
\end{tabular}

$\mathrm{OH}$, oats high; OL, oats low; SBP, systolic blood pressure; DBP, diastolic blood pressure. 
pressure readings were taken using a Dinamap XL Vital Signs Monitor (GE Healthcare, Chalfont St Giles, Buckinghamshire, UK). Body weight and percentage of body fat were measured while standing using bioelectrical impedance scales (Tanita BF-622W; Tanita Corporation of America, Arlington Heights, IL, USA). These scales have been validated and are thought to be a reasonable comparison with dual-energy X-ray absorptiometry as a reference method ${ }^{(26)}$.

Activity and physical discomfort questionnaires were completed at the 3- and 6-week visits. Symptoms were scored on a scale from 1 to 6 , with 1 being no symptoms and 2 to 6 being symptoms of increasing frequency/severity.

\section{Sample size}

Sample size was determined using an ANOVA approach, based on outcomes reported in a 6-week trial that used a similar dosage of oat-derived $\beta$-glucan ${ }^{(27)}$. It was assumed that no change would occur in cholesterol in the control group, with the two intervention groups expected to show a change of $10 \%$ from baseline concentrations, with standard deviations of $10 \%$. Using $\alpha$ values of significance of $0.05-0.01$ and $90 \%$ power, a sample size of between nineteen and twenty-seven participants per group was required. To account for dropout, thirty participants per group were targeted for recruitment.

\section{Statistical analysis}

The primary outcome measures were fasting $(10 \mathrm{~h})$ total and LDL-serum cholesterol. Secondary outcomes were changes in fasting serum HDL, TAG, glucose, insulin and systolic blood pressure. Statistical analysis was performed using SPSS (version 17.0; SPSS, Inc., Chicago, IL, USA). Model assumptions were checked before analysis. The analysis of primary and secondary variables was conducted using a linear mixed model for repeated measures or a general linear model for repeated measures as stated in the text. As weight loss is known to improve lipid, blood pressure, glucose and insulin measures, and weight decreased significantly during the study period in all groups, the analysis of all biochemical variables was adjusted for weight, as a continuous time-varying covariate. Adjusted and unadjusted analyses are presented. (The advantage of the use of the linear mixed model in this analysis is that partial datasets were incorporated and in this way, data from all subjects who commenced the study were included in the analysis.) An exploratory post hoc analysis was also conducted to investigate the effects in the responders. Responders were defined as those subjects who experienced a decrease of any magnitude $(<0.000 \mathrm{mmol} / \mathrm{l})$ in LDL-C ( $n$ 60). Non-responders were those who experienced no change or an increase $(\geq 0.000 \mathrm{mmol} / \mathrm{l})$ in LDL-C ( $n$ 27). The analysis was also conducted in the form of a percentage change from baseline, defined as the difference between the values for week 6 and baseline, expressed as a percentage of the baseline measure. Factors that predicted LDL-responders were investigated using logistic regression analyses. Both univariate and multivariate analyses were conducted in the model building procedure. The following variables were considered in the logistic regression: study group, sex, age, baseline BMI, baseline percentage of body fat, waist circumference, baseline cholesterol, TAG and HDL. Multivariate analysis was conducted using an entry model (where all variables were included) and a backward elimination procedure with exclusion based on the likelihood ratio test. One-way ANOVA or $t$ tests were conducted for the responder analysis with post hoc follow-up of significant results as indicated. Proportions were compared using Pearson's $\chi^{2}$ analysis. Results are presented as means and standard deviations unless otherwise indicated.

\section{Results}

\section{Participants}

Recruitment was conducted continuously over a 13-month period. A total of 328 people expressed interest in the present study and 127 were eligible for the confirmatory blood test, of whom ninety-five (fifty-one females, forty-four males) met the study criteria. Among these, five participants withdrew (four females, one male) before receiving the study foods. Randomisation was conducted for the remaining ninety participants by a researcher independent of the clinical interface (M. J. B.). The male:female composition of each group was 15:15 in the $\mathrm{OH}$ group, 11:17 in the OL group and 15:17 in the control group. Withdrawals after the first counselling visit left $15: 15$ in the $\mathrm{OH}$ group ( $n$ 30), 11:15 in the OL group ( $n$ 26) and 15:16 in the control group ( $n$ 31; Fig. 1 ).

The study sample was middle-aged (51 (SD 10.22) years), overweight (BMI 27.26 (sD $4 \cdot 10) \mathrm{kg} / \mathrm{m}^{2}$ ) men and women with mildly elevated cholesterol levels but otherwise healthy (Table 2). There were no differences between the groups at baseline in the variables measured $(P=0.423-0.954)$.

\section{Clinical outcomes}

All three diet groups produced a reduction in total cholesterol levels (time effect $P<0 \cdot 001$ ), but there was no difference in reduction between the groups (Table 3 and Fig. 2; group effect: $P=0.563$; interaction effect: $P=0.663)$. Similarly, all groups showed reductions in LDL-C (time effect $P<0 \cdot 001$ ) and HDL-cholesterol (time effect: $P<0 \cdot 001$ ), but betweengroup differences were not evident (Fig. 2). No change in TAG was evident (time effect: $P=0 \cdot 279$ ). Since there was no difference in response according to $\beta$-glucan dosage, the $\mathrm{OH}$ and $\mathrm{OL}$ groups were combined and a two-group exploratory analysis was conducted. Percentage reduction from baseline in LDL-C was - 8.42 (SD 17.41) v. - 5.48 (SD 12.36) \% for the $\mathrm{OH}+\mathrm{OL}$ and control groups, respectively $(P=0.363)$, resulting in a mean difference from baseline between the two groups of $-2 \cdot 94$ (SE $3 \cdot 22) \%$.

\section{Subgroup responder analysis}

Subgroup analyses of responders ( $n$ 60) identified a trend towards a greater reduction in LDL-C from baseline at 6 weeks in the $\mathrm{OH}$ and $\mathrm{OL}$ groups $(P=0 \cdot 086$, one-way 


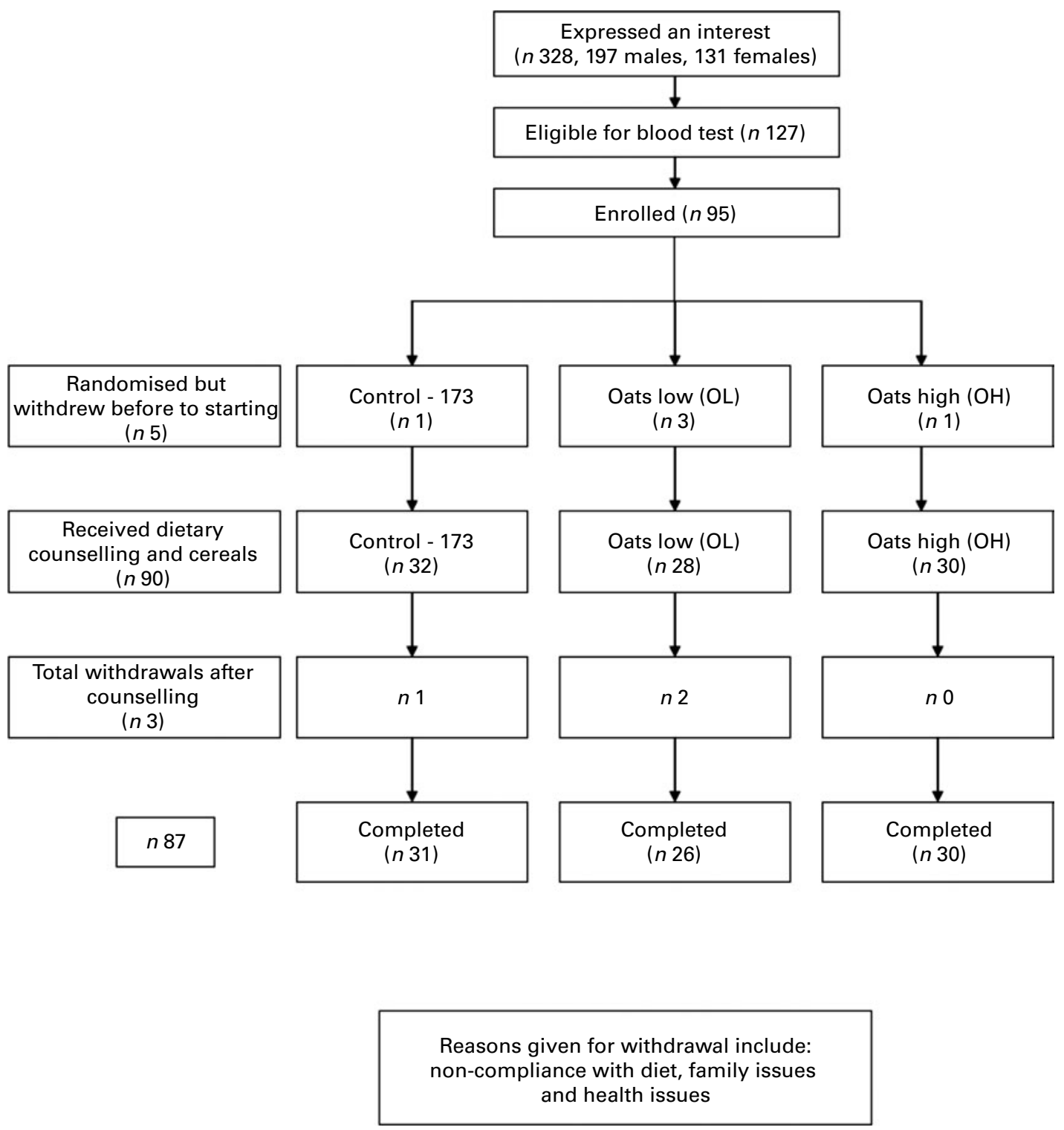

Fig. 1. Flow chart for the study.

ANOVA; Table 4). This difference was significant $(P=0.044$, one-way ANOVA) when LDL-C reduction was expressed as $\%$ change from baseline (-18.3 (SD 11.1)\%, - 18.1 (SD 9.2) \% and -11.7 (SD 7.9) \% in the $\mathrm{OH}$, OL and control groups, respectively), although the post hoc analysis adjusted for multiple comparisons showed that these between-group differences were of borderline significance for the two oat groups $v$. controls $(P=0.067$ and $P=0.097$ for the $\mathrm{OH}$ and $\mathrm{OL}$ groups, respectively; Tukey's honestly significant difference test). Post hoc analyses found no difference in response between the $\mathrm{OH}$ and $\mathrm{OL}$ groups; therefore, a two-group analysis (OH and OL groups combined) was performed. Betweengroup differences from baseline were significant for LDL-C $(-18.2(\mathrm{SD} 10 \cdot 1) \% v$. -11.7 (SD 7.9)\%; mean difference -2.8 (SE $2 \cdot 3$ ) for the $\mathrm{OH}+\mathrm{OL} v$. control groups, respectively; $P=0 \cdot 008)$.

\section{Predictors of $L D L$-responders}

Baseline total cholesterol was the only significant predictor of LDL-responder, both in univariate and multivariate (backward stepwise) logistic regression models; the other variables entered (age, sex, BMI, body fat, TAG and HDL-cholesterol) were not significant. For every one unit increase in total cholesterol, there was a 2.850 times increase in the odds of being a responder $(P=0.026)$. That is, increasing cholesterol is more likely to result in LDL response.

\section{Other outcomes}

There were no significant changes in glucose, insulin or blood pressure measurements. Homeostatic model assessment (HOMA) scores showed no significant difference for time, 
Table 3. Changes in clinical parameters at 0,3 and 6 weeks

(Mean values and standard deviations)

\begin{tabular}{|c|c|c|c|c|c|c|c|c|c|c|c|c|c|c|c|c|c|c|c|c|c|}
\hline \multirow[b]{3}{*}{ Variable } & \multicolumn{6}{|c|}{ Baseline } & \multicolumn{6}{|c|}{3 weeks } & \multicolumn{6}{|c|}{6 weeks } & \multirow{2}{*}{\multicolumn{3}{|c|}{$P$}} \\
\hline & \multicolumn{2}{|c|}{$\mathrm{OH}(n 30)$} & \multicolumn{2}{|c|}{ OL (n 28) } & \multicolumn{2}{|c|}{$\begin{array}{l}\text { Control } \\
(n \text { 32) }\end{array}$} & \multicolumn{2}{|c|}{$\mathrm{OH}(n 30)$} & \multicolumn{2}{|c|}{$\mathrm{OL}(n 26)$} & \multicolumn{2}{|c|}{$\begin{array}{l}\text { Control } \\
\text { (n 31) }\end{array}$} & \multicolumn{2}{|c|}{$\mathrm{OH}(n 30)$} & \multicolumn{2}{|c|}{$\mathrm{OL}(n 26)$} & \multicolumn{2}{|c|}{$\begin{array}{l}\text { Control } \\
(\text { (n 31) }\end{array}$} & & & \\
\hline & Mean & SD & Mean & SD & Mean & SD & Mean & SD & Mean & SD & Mean & SD & Mean & SD & Mean & SD & Mean & SD & Time & Group & Interaction \\
\hline Total cholesterol (mmol/l) & 5.97 & 0.55 & $6 \cdot 12$ & 0.54 & 6.03 & 0.58 & $5 \cdot 40$ & 0.87 & $5 \cdot 40$ & 0.69 & $5 \cdot 52$ & 0.67 & 5.49 & 0.80 & $5 \cdot 68$ & 0.77 & $5 \cdot 67$ & 0.68 & $\begin{array}{l}0.000 \\
0.000^{*}\end{array}$ & $\begin{array}{l}0.691 \\
0.563^{\star}\end{array}$ & $\begin{array}{l}0.684 \\
0.663^{*}\end{array}$ \\
\hline TAG $(\mathrm{mmol} / \mathrm{l})$ & $1 \cdot 37$ & 0.59 & 1.53 & 0.73 & 1.56 & 0.70 & $1 \cdot 23$ & 0.44 & 1.54 & 0.80 & 1.48 & 0.81 & 1.34 & 0.60 & 1.56 & 0.58 & 1.55 & 0.78 & $\begin{array}{l}0.415 \\
0.279^{*}\end{array}$ & $\begin{array}{l}0.305 \\
0.308^{\star}\end{array}$ & $\begin{array}{l}0.921 \\
0.873^{\star}\end{array}$ \\
\hline $\mathrm{HDL}(\mathrm{mmol} / \mathrm{l})$ & 1.53 & 0.31 & 1.61 & 0.56 & 1.45 & 0.37 & 1.43 & 0.32 & 1.46 & 0.55 & 1.32 & 0.35 & 1.42 & 0.31 & 1.48 & 0.52 & 1.36 & 0.37 & $\begin{array}{l}0.000 \\
0.000^{\star}\end{array}$ & $\begin{array}{l}0.462 \\
0.614^{*}\end{array}$ & $\begin{array}{l}0.751 \\
0.580^{\star}\end{array}$ \\
\hline Cholesterol:HDL ratio & 4.06 & 0.83 & $4 \cdot 26$ & 1.51 & $4 \cdot 36$ & 1.01 & 3.88 & 0.72 & 4.09 & 1.37 & 4.43 & 1.14 & 3.99 & 0.79 & $4 \cdot 15$ & $1 \cdot 12$ & 4.45 & $1 \cdot 15$ & $\begin{array}{l}0.286 \\
0 \cdot 165^{\star}\end{array}$ & $\begin{array}{l}0.284 \\
0.565^{\star}\end{array}$ & $\begin{array}{l}0.355 \\
0.346^{\star}\end{array}$ \\
\hline LDL (mmol/l) & 3.82 & 0.56 & 3.84 & 0.67 & 3.86 & 0.55 & 3.40 & 0.77 & 3.24 & 0.70 & 3.52 & 0.57 & 3.46 & 0.69 & 3.49 & 0.70 & 3.60 & 0.53 & $\begin{array}{l}0.000 \\
0.000^{\star}\end{array}$ & $\begin{array}{l}0.460 \\
0.589^{\star}\end{array}$ & $\begin{array}{l}0.435 \\
0.459^{\star}\end{array}$ \\
\hline Glucose $(\mathrm{mmol} / \mathrm{l})$ & $4 \cdot 85$ & 0.46 & 4.96 & 0.53 & $4 \cdot 86$ & 0.38 & 4.91 & 0.43 & 4.92 & 0.54 & $4 \cdot 80$ & 0.45 & $4 \cdot 81$ & 0.51 & $4 \cdot 97$ & 0.61 & $4 \cdot 84$ & 0.32 & $\begin{array}{l}0.717 \\
0.634^{*}\end{array}$ & $\begin{array}{l}0.734 \\
0.473^{*}\end{array}$ & $\begin{array}{l}0.916 \\
0.906^{\star}\end{array}$ \\
\hline Insulin (pmol//) & 8.92 & 3.91 & $10 \cdot 16$ & $8 \cdot 29$ & $9 \cdot 10$ & 4.86 & $6 \cdot 61$ & 3.58 & $9 \cdot 26$ & 8.69 & $7 \cdot 38$ & 4.55 & 8.45 & 7.43 & $8 \cdot 31$ & 8.93 & 7.69 & 4.46 & $\begin{array}{l}0.017 \\
0.505^{*}\end{array}$ & $\begin{array}{l}0.703 \\
0.435^{\star}\end{array}$ & $\begin{array}{l}0.229 \\
0.144^{\star}\end{array}$ \\
\hline $\mathrm{SBP}(\mathrm{mm} / \mathrm{Hg})$ & $128 \cdot 8$ & $20 \cdot 7$ & $132 \cdot 1$ & $17 \cdot 1$ & $131 \cdot 8$ & $20 \cdot 4$ & $124 \cdot 5$ & $19 \cdot 4$ & $131 \cdot 1$ & $17 \cdot 8$ & $123 \cdot 3$ & $16 \cdot 5$ & $123 \cdot 2$ & $17 \cdot 8$ & $127 \cdot 4$ & $15 \cdot 3$ & $122 \cdot 9$ & $16 \cdot 3$ & $\begin{array}{l}0.000 \\
0.000^{\star}\end{array}$ & $\begin{array}{l}0.643 \\
0.556^{*}\end{array}$ & $\begin{array}{l}0.431 \\
0.402^{*}\end{array}$ \\
\hline Weight & $77 \cdot 1$ & $10 \cdot 7$ & $77 \cdot 9$ & $16 \cdot 4$ & $81 \cdot 1$ & $14 \cdot 2$ & $76 \cdot 7$ & $10 \cdot 5$ & $76 \cdot 5$ & $16 \cdot 1$ & $80 \cdot 3$ & $14 \cdot 2$ & $75 \cdot 6$ & $10 \cdot 6$ & $74 \cdot 0$ & $13 \cdot 4$ & $80 \cdot 3$ & 14.4 & 0.000 & 0.436 & 0.132 \\
\hline Physical activity (Baecke) & 7.93 & $1 \cdot 24$ & 8.13 & $1 \cdot 24$ & $7 \cdot 80$ & $1 \cdot 11$ & & & & & & & 8.05 & 1.32 & 8.34 & 1.26 & 7.93 & $1 \cdot 20$ & 0.181 & 0.576 & 0.969 \\
\hline
\end{tabular}

$\mathrm{OH}$, oats high; OL, oats low; SBP, systolic blood pressure.

* Adjusted for weight change. 


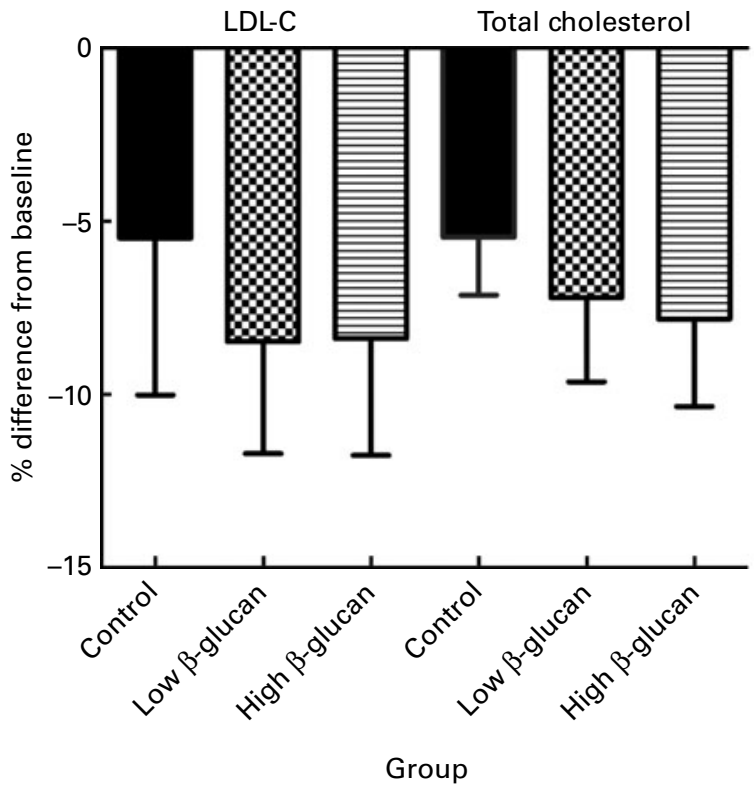

Fig. 2. Mean change at 6 weeks, expressed as a percentage of baseline values, in total cholesterol and LDL-cholesterol (LDL-C) by diet group, with standard errors represented by vertical bars.

group or interaction $(P>0 \cdot 05$, linear mixed model). All groups lost weight (time effect: $P=0.005$; linear mixed model), with no difference between the groups (Table 3). After 3 weeks, all groups lost an average of $1.0(\mathrm{SD} 1.32) \mathrm{kg}$ and the two intervention groups continued to lose about $50 \%$ more in the second 3-week period (0.64 (SD 0.78) and $0.62(\mathrm{SD} 0.78) \mathrm{kg}$, respectively). All groups decreased their percentage of body fat $(-0.45(\mathrm{SD} 2.30),-1.28(\mathrm{SD} 1.84)$ and -0.57 (SD 1.32) in the $\mathrm{OH}, \mathrm{OL}$ and control groups, respectively; $P=0.263$; linear mixed model)

Dietary compliance. There were no significant interaction effects between diet groups for energy and macronutrient intakes $(P>0.05)$. All groups reported reductions in energy intakes (time effect: $P<0.001$ ), and in percentage of energy from total fat and saturated fat (time effect: $P<0 \cdot 001$ ). All groups reported increases in percentage of energy from protein and in polyunsaturated:saturated (P:S) ratio (time effect: $P<0.001$; Table 5). Even though the participants were modelled for weight maintenance, by providing low-fat healthy eating advice, the oral intake of participants changed. Participants reduced, limited or completely removed high-energy, lownutrient snack foods (e.g. potato crisps, chocolate, pastries) and alcohol from their regular eating patterns. A shift in energy consumption may have occurred by removing and limiting these foods and beverages from their diets, even when they were replaced with other foods.

Compliance with consumption of the test and control foods was high. All groups consumed both the breakfast cereal and cereal bar products equally. Of the forty-two serves of each pack provided, the control group consumed a mean of 38 (SD 4) cereals and 37 (SD 5) bars, comparing well with the 39 (SD 3) and 39 (SD 2) in the OL group and 37 (SD 5) and 36 (SD 8) in the $\mathrm{OH}$ group. Based on returned test product packets, only three subjects had compliance of less than $50 \%$, but these participants were not excluded as intention-to-treat analyses were performed. No linear relationship between compliance and LDL-C change was demonstrated $(r-0 \cdot 149, \quad P=0 \cdot 277)$. Participants were able to consume the $60 \mathrm{~g}$ serving sizes of oats-containing cereals with no reported difficulty.

Due to the low number of reported symptoms of rating 3 or higher, data were recorded as no symptoms or symptoms and compared between the groups using $\chi^{2}$ analysis. There was no significant difference between the groups in the frequency of reported gastrointestinal symptoms on flatulence, bloating and diarrhoea $(P=0.442,0.201$ and 0.467 , respectively). There were no reported adverse events. There were no significant changes in the levels of physical activity between or within the groups during the intervention (Table 3).

Physico-chemical properties of test foods. The laboratory results for the physico-chemical properties of each of the test foods are shown in Table 1. The control samples contained insignificant levels of $\beta$-glucan. The physiological extraction procedure was performed on these products and the viscosity of the extract from the puffed rice bar was $1.23 \mathrm{mPa}$ and the cornflake extract had a viscosity of $0.93 \mathrm{mPa}$ s (measured at 32 per second), which was close to the viscosity of water $\left(0.72 \mathrm{mPas}\right.$ at $\left.37^{\circ} \mathrm{C}\right)$. The $\beta$-glucan-containing foods had higher extract viscosities. The viscosities of the extracts from

Table 4. Change in LDL-cholesterol (LDL-C), according to the total group and LDL-C responders only

(Baseline measures, standard deviations and number of subjects)

\begin{tabular}{|c|c|c|c|c|c|c|c|}
\hline Group & $\begin{array}{l}\text { Change from } \\
\text { baseline }(\mathrm{mmol} / \mathrm{l})\end{array}$ & SD & $\begin{array}{c}P \text { (one-way } \\
\text { ANOVA) }\end{array}$ & $n$ & $\begin{array}{l}\text { Change from } \\
\text { baseline (\%) }\end{array}$ & SD & $\begin{array}{c}P \text { (one-way } \\
\text { ANOVA) }\end{array}$ \\
\hline \multicolumn{8}{|l|}{ LDL-C } \\
\hline \multicolumn{8}{|l|}{ Total group } \\
\hline $\mathrm{OH}$ & -0.360 & 0.730 & 0.692 & 30 & -8.38 & 18.46 & 0.712 \\
\hline $\mathrm{OL}$ & -0.365 & 0.651 & & 26 & -8.47 & 16.49 & \\
\hline Control & -0.242 & 0.482 & & 31 & -5.48 & 12.36 & \\
\hline \multicolumn{8}{|c|}{ Responders } \\
\hline $\mathrm{OH}$ & -0.738 & 0.489 & 0.086 & 21 & -18.27 & $11 \cdot 10$ & $0.044^{*}$ \\
\hline $\mathrm{OL}$ & -0.729 & 0.447 & & 17 & $-18 \cdot 12$ & $9 \cdot 17$ & \\
\hline Control & -0.473 & 0.355 & & 22 & -11.68 & 7.87 & \\
\hline
\end{tabular}

$\mathrm{OH}$, oats high; $\mathrm{OL}$, oats low.

* Post hoc analysis showed that the reduction in LDL-C was less in the control group than in the intervention groups; however, the differences were not significant when adjusted for multiple comparisons ( $P=0.067$ and 0.097 for the $\mathrm{OH}$ and OL groups, respectively; Tukey's honestly significant difference test). 
the cereal bar and the RTE oat flakes were quite similar despite having different molecular weights and solubilities. The cereal bar had low $\beta$-glucan solubility (24.09\% of total), probably because of low water availability during processing, and the molecular weight was similar to the molecular weight in oat bran $^{(23)}$. The RTE oat flakes had much higher solubility (90.62\% of total) because of the high temperatures and water availability during processing. The increase in $\beta$-glucan in solution was offset by a reduction in molecular weight which can be caused by very high shear. The viscosity of the extract from the rolled oats was the highest, with the solubility and molecular weight of $\beta$-glucan typical of oatmeal and oat bran.

The development of viscosity in the gut has been shown to be related to the physiological functioning of oat $\beta$-glucan ${ }^{(6)}$. Since only the soluble portion of $\beta$-glucan contributes to viscosity development, it is more physiologically active than the insoluble portion. Taking into account the solubility of $\beta$-glucan in each test food, the dose of soluble $\beta$-glucan was calculated. The OL group consumed $1.32 \mathrm{~g}$ soluble $\beta$-glucan provided by the RTE oat flakes, whereas the $\mathrm{OH}$ group consumed $1.08 \mathrm{~g}$ soluble $\beta$-glucan from the combination of rolled oat porridge and cereal bar. So, although the total dose was higher for the $\mathrm{OH}$ group, they received slightly less of the physiologically active soluble $\beta$-glucan.

\section{Discussion}

For this sample of otherwise healthy overweight adults with mild hypercholesterolaemia, we found significant cholesterol-lowering effects with a low-fat and low-saturated-fat diet, with and without 1.5 or $3.0 \mathrm{~g}$ oat $\beta$-glucan/d delivered in three different food forms. Despite the effects of the healthy low-fat diet in all groups, it is possible that other factors, such as differences in metabolism, may have influenced our ability to differentiate between the groups. The secondary analysis of responder data suggests that this may be the case, showing a higher reduction in LDL-C with oat $\beta$-glucan compared with the control diet (18\%v. 11\%; $P=0.04)$.

Meta-analyses have demonstrated that a daily intake of $3 \mathrm{~g}$ $\beta$-glucan/d can lower LDL-C concentrations by about $4 \%$ or $0.13 \mathrm{mmol} / \mathrm{l}^{(1,28)}$. It is generally accepted that for every $1 \%$ lowering of serum cholesterol levels, the risk of development of CHD is reduced by $2-3 \%{ }^{(18)}$. In the present study, the oat groups had reductions in LDL-C from baseline in the region of approximately $8.4 \%$, at $\beta$-glucan doses of either 1.5 or $3 \mathrm{~g} / \mathrm{d}$. The magnitude of this effect is similar to that reported in a recent 12 -week weight loss study in which the $3 \mathrm{~g} / \mathrm{d} \beta$-glucan group reduced LDL-C by $8.7 \%$, compared with the control group $(-4.3 \%)^{(18,29)}$. The present study also reported higher reductions in total cholesterol over 6 weeks $(-7 \cdot 8 \%)$ compared with that study $(-5.4 \%)$; however, the lack of between-group differences compared with the control group in the present study is related to a higherthan-expected cholesterol-lowering effect in the control group which adopted a low-fat eating pattern for 6 weeks. It should be noted that the Maki et $a l .{ }^{(29)}$ study reported a significant between-group difference for total cholesterol only in per-protocol analyses which included participants who 
were at least $80 \%$ compliant with study product consumption and had no major protocol violations. Their intention-to-treat analysis failed to demonstrate significant differences between the groups, even with a large sample size of 174 participants; so again, it may be worth pursuing the characteristics of responders in future studies that aim to expose the effects of $\beta$-glucan delivered in various food forms and dosages.

A recent systematic review of the consistent association between oat consumption and cardiovascular risk factors ${ }^{(30)}$ also found one study that showed cholesterol reduction in all groups including the low-fat control diet ${ }^{(31)}$. In our case, the healthy background diet appeared to influence weight, bearing in mind that weight loss alone can improve lipid profiles $^{(32)}$. In addition, concurrent changes in dietary fat occurred in the sample, including the displacement of saturated fat, which may confound the relationship between increased fibre intake and blood cholesterol levels ${ }^{(33)}$. In the study reported here, we did not show effects on TAG, but the lowered HDL-cholesterol produced by the sample was consistent with the lower reported intake of dietary fat $(<30 \mathrm{E} \%)$. A recent meta-analysis of thirty controlled feeding studies $^{(34)}$ showed that both modified-fat $(30-50 \mathrm{E} \%)$ and low-fat (18-30\%) diets lower LDL-C, but modified-fat diets tend to lower HDL-cholesterol less, and may produce greater reductions in TAG. Finally, in the present study, the lack of effects on the secondary outcomes of blood pressure, glucose, insulin and homeostasis model assessment (HOMA) indices probably reflected the relatively short period of study and the normal baseline levels recorded.

The present results may also have been influenced by the food matrix of the intervention foods. When oat-derived $\beta$-glucan was incorporated into bread and cookies and provided at a level of $6 \mathrm{~g} / \mathrm{d}$ for 4 weeks, no cholesterol-lowering effect was observed ${ }^{(35)}$. The authors concluded that the food matrix or the food processing, or both, may be influential in limiting the cholesterol-lowering properties of oat bran. In particular, a high-molecular-weight $\beta$-glucan molecule can entangle to form viscous solutions ${ }^{(36)}$ and high solubility must be maintained to ensure this effect. Reduction in molecular weight or solubility will therefore effect viscosity and have follow-on effects on physiological functionality. It has previously been shown that the viscosity of the in vitro extract of oat-containing foods positively correlates with cholesterol reduction $^{(6,23)}$ and also glycaemic response $\mathrm{e}^{(17,37)}$ and the satiety biomarkers cholecystokinin ${ }^{(16)}$ and peptide $\mathrm{YY}^{(38)}$. The viscosity of $\beta$-glucan solutions is dependent mainly on the concentration of $\beta$-glucan in solution and its molecular weight.

In the present study, the $\mathrm{OH}$ and $\mathrm{OL}(3 \mathrm{~g} \beta$-glucan and $1.5 \mathrm{~g}$ $\beta$-glucan, respectively) test foods had near-equal cholesterollowering effects; yet molecular weights, solubility and viscosities were variable. Using viscosity as a measure of bioactivity, it could be expected that in the present study, cholesterol reduction should have been greater in $\mathrm{OH} v$. OL as the viscosity of rolled oats was higher (16.03) than the extruded oat flakes. Similarly, the molecular weight of $\beta$-glucan was also higher in both the rolled oats and cereal bar (OH group; 2100000 v. $2400000 \mathrm{~g} / \mathrm{mol}$, respectively) than in the extruded oat flakes (OL group; $760000 \mathrm{~g} / \mathrm{mol}$ ).
However, previous studies have shown that high and medium molecular weights of $\beta$-glucan such as those of the two groups in the present study can significantly reduce LDL-C ${ }^{(6)}$ and modulate the blood glucose response ${ }^{(37)}$. It was also shown in the present study that the dose of solubilised $\beta$-glucan was comparable ( 1.32 in $\mathrm{OL} v .1 .08 \mathrm{~g}$ in $\mathrm{OH}$ ) across the two intervention groups, which may also explain the similar results observed. Nevertheless, the present findings in the study reported here are consistent with other studies demonstrating that extrusion to produce an oats-containing breakfast cereal may only slightly decrease molecular weight yet increase solubility of $\beta$-glucan, compared with regular oats that have higher molecular weight with poorer solubility ${ }^{(16)}$

To take into account the drop in viscosity caused by partial depolymerisation in the RTE oat flakes during processing, the parameter $M_{\mathrm{p}} \times C$ was calculated, where $M_{\mathrm{p}}$ is the molecular weight of the $\beta$-glucan in solution and $C$ is the daily dose of soluble $\beta$-glucan. Wolever et al. ${ }^{(6)}$ suggest that $M_{\mathrm{p}} \times C$ may be a more robust measure of $\beta$-glucan bioactivity than the viscosity of extracted $\beta$-glucan, because molecular weight and $C$ are relatively insensitive to extrinsic factors ${ }^{(6)}$. The $M_{\mathrm{p}} \times C$ value for the $\mathrm{OH}$ treatment was 1600 , whereas it was 1000 in the OL treatment. The similarity in these values may explain the similar reduction in cholesterol achieved with the two treatments in the present study. For comparison, these values are not that dissimilar to the values found for treatments at concentrations of $3 \mathrm{~g} \beta$-glucan/d of medium molecular weight $\left(M_{\mathrm{p}}=528000\right)(3 \mathrm{M})$ and $4 \mathrm{~g} \beta$-glucan $/ \mathrm{d}$ of low molecular weight $\left(M_{\mathrm{p}}=211000\right)(4 \mathrm{~L})$ for extruded oat bran cereals studied previously ${ }^{(6)}$. In that study, the $3 \mathrm{M}$ cereal had an $M_{\mathrm{p}} \times C$ value of 1500 and significantly lowered LDLC by $4.7 \%(P=0 \cdot 012 ; n$ 64). However, the $4 \mathrm{~L}$ cereal produced a non-significant LDL-C lowering of $2 \cdot 3 \%(P=0 \cdot 205 ; n$ 63), with an $M_{\mathrm{p}} \times C$ value of 840 . This may be due to the low $M_{\mathrm{p}} \times C$ value reflecting a potentially lower bioactivity of the $\beta$-glucan. It should also be considered that the larger number of participants in the oat bran cereal study may have increased the ability to distinguish differences between the treatment and control groups compared with the present study in which less than half that number of participants ( $n$ 30) were randomised to the $\mathrm{OH}(3 \mathrm{~g} \beta$-glucan) treatment group.

There are a number of potential limitations to the present study. The study may have been under-powered, since sample size was determined assuming that no change in serum cholesterol from baseline would occur in the control group and that weight would remain stable in all groups. Further, the expected magnitude of reduction in LDL-C of $10 \%$ in the two intervention groups ${ }^{(25)}$ appears to have been too optimistic. The finding from secondary analyses that a higher baseline total cholesterol was predictive of LDL response to $\beta$-glucan consumption in responders is consistent with previous studies ${ }^{(1)}$, but regression to the mean ${ }^{(39)}$ may have been a confounder in this analysis.

In conclusion, favourable reductions in total and LDL-C in healthy diets with oat $\beta$-glucan are supported by strong mechanistic evidence of oat $\beta$-glucan on cholesterol levels. However, in the present study, the incorporation of $\beta$-glucan 
from oat foods into a healthy low-fat diet for 6 weeks did not lead to a further significant decrease in serum cholesterol compared with a low-fat diet alone. No effect of the intervention diets was observed regarding the secondary outcomes (glucose, insulin resistance and blood pressure). The findings from the present study suggest that a smaller quantity $(1.5 \mathrm{~g} /$ d) of medium-molecular-weight oat $\beta$-glucan with high solubility may be equally as effective as a higher quantity $(3 \mathrm{~g} / \mathrm{d})$ of high-molecular-weight $\beta$-glucan. Further examination of these factors is warranted to assist in determining the lowest effective doses of oat $\beta$-glucan within different food matrices that may be influential in effectively reducing cholesterol in moderately hypercholesterolaemic populations.

\section{Acknowledgements}

Financial support for the present study was provided by a research grant from Cereal Partners Worldwide Limited. Dr Yasmine Probst is thanked for her assistance with the analysis of dietary intake, Ms Holley Jones for initial inputs into project management and Mr Kiefer Zhang for some data collection. None of the authors has any conflicts of interest to declare. K. E. C. was involved in the conceptualisation of the study design, overall management of the project and primarily responsible for manuscript writing. L. C. T. was responsible for the conceptualisation of the study design and editing of the manuscript. M. J. B. contributed to the sampling and randomisation, statistical data analysis, data interpretation and editing of the manuscript. J. O. was involved in the data collection, data entry and overall data management, and editing of the manuscript. R. T. was responsible for the data collection, data entry and editing of the manuscript. E. B. contributed to the methodology and editing of the manuscript. S. M. T. conducted the physico-chemical analyses of the test foods, and was involved in the interpretation of the data analyses and editing of the manuscript.

\section{References}

1. Ripsin C, Keenan J, Jacobs DJ, et al. (1992) Oat products and lipid lowering: a meta-analysis. JAMA 267, 3117-3325.

2. Brown L, Rosner B, Willett W, et al. (1999) Cholesterollowering effects of dietary fibre: a meta-analysis. Am J Clin Nutr 69, 30-42.

3. Poppitt S (2007) Soluble fibre oat and barley $\beta$-glucan enriched products: can we predict cholesterol-lowering effects? Br J Nutr 97, 1049-1050.

4. Keogh G, Cooper G, Mulvey T, et al. (2003) Randomized controlled crossover study of the effect of highly $\beta$-glucan enriched barley on cardiovascular disease risk in mildly hypercholesterolaemic men. Am J Clin Nutr 778, 711-718.

5. Naumann E, van Rees A, Onning G, et al. (2006) Beta-glucan incorporated into a fruit drink effectively lowers serum LDLcholesterol concentrations. Am J Clin Nutr 83, 601-605.

6. Wolever TMS, Tosh SM, Gibbs AL, et al. (2010) Physicochemical properties of oat \{beta\}-glucan influence its ability to reduce serum LDL cholesterol in humans: a randomized clinical trial. Am J Clin Nutr 92, 723-732.

7. Andersson M, Ellegard L \& Andersson H (2002) Oat bran stimulates bile acid synthesis within $8 \mathrm{~h}$ as measured by $7 \alpha$-hydroxy-4-cholesten-3-one. Am J Clin Nutr 76, 1111-1116.

8. Zhang JX, Hallmans G, Andersson H, et al. (1992) Effect of oat bran on plasma-cholesterol and bile-acid excretion in 9 subjects with ileostomies. Am J Clin Nutr 56, 99-105.

9. Ellegard L \& Andersson H (2007) Oat bran rapidly increases bile acid excretion and bile acid synthesis: an ileostomy study. Eur J Clin Nutr 61, 938-945.

10. Lia A, Andersson H, Mekki N, et al. (1997) Postprandial lipemia in relation to sterol and fat excretion in ileostomy subjects given oat-bran and wheat test meals. Am J Clin Nutr 66, 357-365.

11. Wursch P \& Pi-Sunyer F (1997) The role of viscous soluble fibre in the metabolic control of diabetes - a review with special emphasis on cereals rich in beta-glucan. Diabetes Care 20, 1774-1780.

12. McLeary B (2001) Measurement of Dietary Fibre Components: The Importance of Enzyme Purity, Activity and Specificity. London: Blackwell Science.

13. Aman P, Rimsten L \& Andersson R (2004) Molecular weight distribution of $\beta$-glucan in oat-based foods. Cereal Chem 81, 356-360.

14. Beer M, Wood P, Weisz J, et al. (1997) Effect of cooking and storage on the amount and molecular weight of $(1 \rightarrow 3)(1 \rightarrow 4)-\beta$-D-glucan extracted from oat products by an in vitro digestion system. Cereal Chem 74, 705-709.

15. Regand A, Tosh SM, Wolever TM, et al. (2009) Physicochemical properties of beta-glucan in differently processed oat foods influence glycemic response. J Agric Food Chem 57, 8831-8838.

16. Beck EJ, Tosh SM, Batterham MJ, et al. (2009) Oat $\beta$-glucan increases postprandial cholecystokinin levels, decreases insulin response and extends subjective satiety in overweight subjects. Mol Nutr Food Res 53, 1343-1351.

17. Lan-Pidhainy X, Brummer Y, Tosh S, et al. (2007) Reducing $\beta$-glucan solubility in oat bran muffins by freeze-thaw treatment attenuates its hypoglycemic effect. Cereal Chem 84, $512-517$.

18. Wood P (2007) Cereal $\beta$-glucan in diet and health. J Cereal Sci 46, 230-238.

19. Food and Drug Administration (1997) Soluble fibre from whole oats and coronary heart disease health claim. Fed Regist 62, 3583-3601.

20. EFSA (2010) Scientific Opinion on the Substantiation of a Health Claim Related to Oat Beta Glucan and Lowering Blood Cholesterol and Reduced Risk of (Coronary) Heart Disease Pursuant to Article 14 of Regulation (EC) No. 1924/2006. [NaAN Panel on Dietetic Products, editor]. Parma, Italy: EFSA Journal, pp. 1885-1899.

21. Agence Française de Sécurité Sanitaire des Aliments (2008) de l'Agence française de sécurité sanitaire des aliments relatif à la demande d'évaluation du fondement scientifique de l'allégation relative à l'effet des fibres solubles d'avoine consommées au sein d'un régime adapté sur le cholestérol sanguin (of the French Agency for Food Safety on the Application for Assessment of Scientific Basis for the Allegation to the Effect of Oat Soluble Fiber Consumed in an Adequate Diet on Blood Cholesterol). French Agency for Food, Environment and Occupational Health \& Safety. http:// www.afssa.fr/Documents/NUT2007sa0168.pdf (accessed 10 March 2011).

22. Health Canada (2010) Oat Products and Blood Cholesterol Lowering Summary of Assessment of a Health Claim about Oat Products and Blood Cholesterol Lowering. Ottawa, ON: Bureau of Nutritional Sciences, Food Directorate, Health Products and Food Branch. http://www.hc-sc.gc.ca/ 
fn-an/label-etiquet/claims-reclam/assess-evalu/oat-avoine-eng. php (accessed 28 February 2011).

23. Tosh SM, Brummer Y, Miller SS, et al. (2010) Processing affects the physicochemical properties of $\beta$-glucan in oat bran cereal. J Agric Food Chem 58, 7723-7730.

24. National Heart Foundation of Australia Healthy Eating Recommendations; available at http://www.heartfoundation. org.au?Healthy_Living/Eating_and_Drinking.htm

25. Mifflin M, St Jeor S, Hill L, et al. (1990) A new predictive equation for testing energy expenditure in healthy individuals. Am J Clin Nutr 51, 241-247.

26. Batterham M, Tapsell L \& Jenkins A (2002) A comparison of bioelectrical impedance and near infra-red interactance with dual energy X-ray absorptiometry for the determination of body fat. Nutr Diet 59, 120-126.

27. Gerhardt AL \& Gallo NB (1998) Full-fat rice bran and oat bran similarly reduce hypercholesterolemia in humans. J Nutr 128, 865-869.

28. Brown L, Rosner B, Willett W, et al. (1999) Cholesterollowering effects of dietary fiber: a meta-analysis. Am J Clin Nutr 69, 30-42.

29. Maki KC, Beiseigel JM, Jonnalagadda SS, et al. (2010) Wholegrain ready-to-eat oat cereal, as part of a dietary program for weight loss, reduces low-density lipoprotein cholesterol in adults with overweight and obesity more than a dietary program including low-fiber control foods. J Am Diet Assoc 110, 205-214.

30. Ruxton C \& Derbyshire E (2008) A systematic review of the association between cardiovascular risk factors and regular consumption of oats. Br Food J 110, 1119-1132.
31. Denmark-Wahnefried W, Bowering J \& Cohen P (1990) Reduced serum cholesterol with dietary change using fatmodified and oat bran supplemented diets. J Am Diet Assoc 90, 223-239.

32. Tapsell L, Batterham M, Teuss G, et al. (2009) Long-term effects of increased dietary polyunsaturated fat from walnuts on metabolic parameters in type II diabetes. Eur J Clin Nutr 63, 1008-1015.

33. Butt M, Tahir-Nadeem M, Khan M, et al. (2008) Oat: unique among the cereals. Eur J Nutr 47, 68-79.

34. Cao Y, Mauger D, Pelkman C, et al. (2009) Effects of moderate (MF) versus lower fat (LF) diets on lipids and lipoproteins: a meta-analysis of clinical trials in subjects with and without diabetes. J Clin Lipidol 3, 19-32.

35. Kerchoffs D, Hornstra G \& Mensink R (2003) Cholesterollowering effect of $\beta$-glucan from oat bran in mildly hypercholesterolaemic subjects may decrease when $\beta$-glucan is incorporated into bread and cookies. Am J Clin Nutr 78, 221-227.

36. Anttila H, Sontag-Strohm T \& Salovaara H (2004) Viscosity of beta-glucan in oat products. J Agric Food Sci 13, 80-87.

37. Tosh S, Brummer Y, Wolever T, et al. (2008) Glycemic response to oat bran muffins treated to vary molecular weight of [beta]-glucan. Cereal Chem 85, 211.

38. Beck EJ, Tapsell LC, Batterham MJ, et al. (2009) Increases in peptide $\mathrm{Y}-\mathrm{Y}$ levels following oat $\beta$-glucan ingestion are dose-dependent in overweight adults. Nutr Res 29, 705-709.

39. Bland J \& Altman D (1994) Regression towards the mean. Br Med J 308, 499 